\title{
Astragaloside IV Downregulates $\beta$-Catenin in Rat Keratinocytes to Counter LiCl-Induced Inhibition of Proliferation and Migration
}

\author{
Fu-Lun Li, ${ }^{1}$ Xin Li, ${ }^{1}$ Yi-Fei Wang, ${ }^{1}$ Xiu-Li Xiao, ${ }^{2}$ Rong Xu, ${ }^{1}$ Jie Chen, ${ }^{1}$ Bin Fan, ${ }^{1}$ \\ Wen-bin $\mathrm{Xu},{ }^{1}$ Lin Geng, ${ }^{1}$ and Bin $\mathrm{Li}^{1}$ \\ ${ }^{1}$ Department of Dermatology, Yueyang Hospital of Integrated Traditional Chinese and Western Medicine, \\ Shanghai University of Traditional Chinese Medicine, Shanghai 200437, China \\ ${ }^{2}$ Baoshan Branch, Shuguang Hospital, Shanghai University of Traditional Chinese Medicine and Pharmacy, Shanghai 201900, China
}

Correspondence should be addressed to Bin Li, drlibin888@yahoo.com.cn

Received 2 October 2011; Accepted 5 February 2012

Academic Editor: Esra Küpeli Akkol

Copyright $\odot 2012$ Fu-Lun Li et al. This is an open access article distributed under the Creative Commons Attribution License, which permits unrestricted use, distribution, and reproduction in any medium, provided the original work is properly cited.

\begin{abstract}
Re-epithelialization is a crucial step towards wound healing. The traditional Chinese medicine, Astragalus membranaceus (Fisch) Bge, has been used for hundreds of years for many kinds of ulcerated wounds. Recent research has identified the active compound in this drug as astragaloside IV (AS-IV), but the underlying molecular mechanisms of its therapeutic action on keratinocytes remain poorly understood. In this study, we used an in vitro model of ulcer-like wound processes, lithium chloride (LiCl)-induced cultured mouse keratinocytes, to investigate the effects of AS-IV treatment. The effects on cell proliferation were evaluated by the MTS/PMS colorimetric assay, effects on cell migration were determined by a wound-healing scratch experiment, effects on the cell cycle were analyzed by flow cytometry, and effects on protein expression were analyzed by immunoblotting and immunofluorescence. LiCl strongly inhibited cell proliferation and migration, up-regulated $\beta$-catenin expression, and down-regulated proliferating cell nuclear antigen (PCNA) expression. AS-IV treatment attenuat the inhibition of proliferation and migration, significantly reducing the enhanced $\beta$-catenin expression, and recovering PCNA and $\beta$-tubulin expression. Thus, AS-IV mediates mouse keratinocyte proliferation and migration via regulation of the Wnt signaling pathway. Down-regulating $\beta$-catenin to increase keratinocyte migration and proliferation is one mechanism by which AS-IV can promote ulcerated wound healing.
\end{abstract}

\section{Introduction}

The skin of all animals provides a protective barrier against entry by pathogens and environmental toxins. Skin cells also encompass a rich molecular infrastructure that involves immune system processes, which further defend against disease or injury to the underlying organs. Thus, cutaneous wounds not only affect skin homeostasis, but also represent a systemic threat; thus, the wound healing process is critical for general health and well-being [1]. The wound healing process is intricate and not yet fully understood; however, it is known that many underlying conditions, such as diabetes, cancer, and vascular disease, can prolong or block the process. In those cases, normal trauma caused by a simple accident or fall can become an ulcerated chronic wound, significantly impacting one's quality of life and increasing the risk of death.

For many centuries, the world's physicians have sought out methods and therapeutic agents that will promote and accelerate wound healing [2]. Generally, the cutaneous wound healing process can be divided into three overlapping, but distinct, phases: the inflammatory phase, the proliferative phase (neoangiogenesis, tissue formation, reepithelialization) and the tissue remodeling phase [3-5]. Reepithelialization is considered a crucial step towards wound healing, and impairment of this process has been demonstrated to result in the development of chronic wounds [6].

The traditional Chinese medicine, Astragalus membranaceus (Fisch) Bge, has long been used to treat ulcerated wounds. Recently, the main active compound from this drug, 


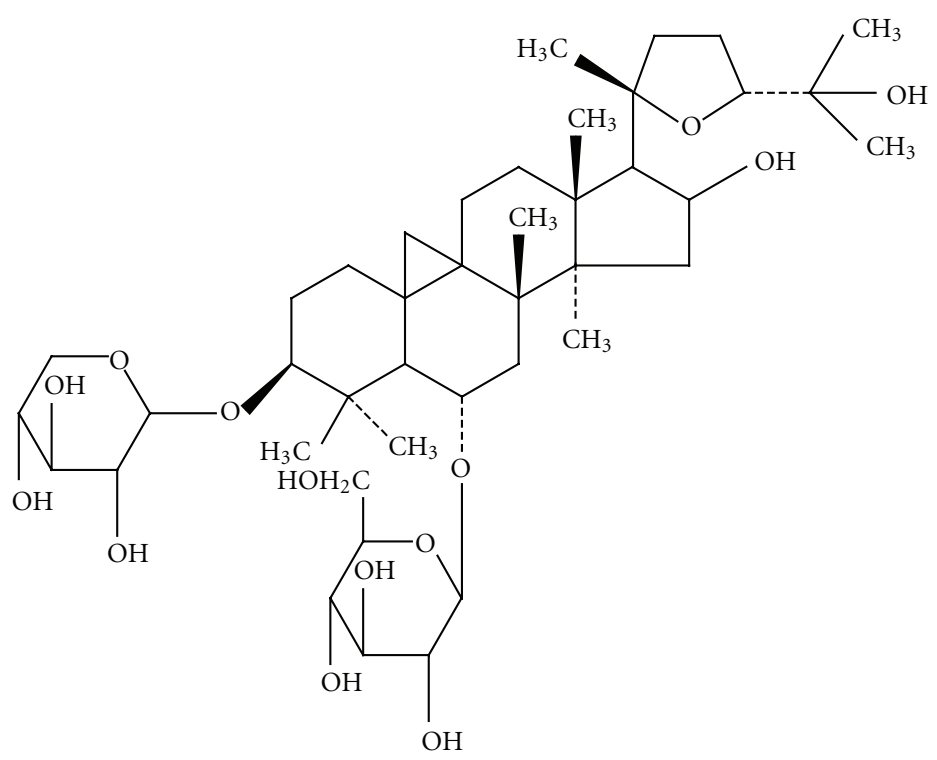

Figure 1: Chemical structure of astragaloside IV.

astragaloside IV (AS-IV), a 3-O- $\beta$-D-xylopyranosyl-6-O- $\beta$ D-glucopyranosylcycloastragenol (chemical structure shown in Figure 1), was purified. Research studies into the biological properties of AS-IV have revealed strong anti-inflammatory activity, which involves inhibition of NF- $\kappa \mathrm{B}$ activation and downregulation of adhesion molecule expression [7]. In addition, many other pharmacological activities have been demonstrated, including antidiabetic and antioxidative activities [8]. However, the precise mechanisms by which AS-IV promotes wound healing remain to be elucidated. In order to develop this Chinese herb as a bona fide therapeutic agent to treat aberrant wound healing, it is necessary to gain a detailed understanding of the involved cellular and molecular mechanisms.

It is known that activation of $\beta$-catenin/c-myc pathways can inhibit keratinocyte migration and differentiation, thereby impairing wound healing [9]. Prior studies using embryological models indicated that administration of lithium chloride $(\mathrm{LiCl})$ can induce signaling pathways that mimic Wnt $/ \beta$-catenin activation. Specifically, LiCl treatment inhibits GSK-3 $\beta$ activity by inducing phosphorylation at Ser-9 [10], which in turn, stabilizes free cytosolic $\beta$-catenin. Thus, in vitro treatment of cultured keratinocytes with $\mathrm{LiCl}$ allows for the controlled experimental analysis of the molecular processes underlying impeded wound healing.

Activated $\beta$-catenin and c-myc have been clinically detected in the epidermis of chronic wounds. As such, it has been proposed that these molecules may serve as markers of impaired healing and may represent useful targets of therapeutic intervention [9]. In a previous study, we demonstrated that diabetic skin ulcers can be efficiently managed by treatment with a Chinese medicine cocktail that includes Astragalus membranaceus (Fisch) Bge. We hypothesized that the mechanism of action might involve inhibition of the Wnt signaling pathway [11]. The study presented herein was designed to investigate the potential effects of AS-IV on $\mathrm{Wnt} / \beta$-catenin signaling in primary keratinocytes under $\mathrm{LiCl}$-induced conditions. These findings reveal a positive role for AS-IV in cutaneous wound healing via downregulation of $\beta$-catenin expression.

\section{Materials and Methods}

2.1. Chemicals and Reagents. AS-IV (99.2\% purity) was purchased from the National Institute for the Control of Pharmaceutical and Biological Products (Shanghai, People's Republic of China) and completely dissolved in room temperature DMSO at a stock concentration of $20 \mathrm{mg} / \mathrm{mL}$. DAPI was purchased from Roche Diagnostic Corp. (Indianapolis, IN, USA). Bromodeoxyuridine (BrdU) detection kit was purchased from BD Biosciences (San Diego, CA, USA). LiC1 (pro analysis grade) was from Sigma-Aldrich (St. Louis, MO, USA). Antibodies against $\beta$-catenin and GAPDH were purchased from Cell Signaling Technology (Beverly, MA, USA). Guinea pig anti-K14 was purchased from RDIFitzgerald (Oaklyn, NJ, USA). Antibody against $\beta$-tubulin was purchased from Sigma-Aldrich. Immunofluorescence secondary antibodies, Alexa Fluor 488-conjugated (green) and Alexa Fluor 594-conjugated (red), were from Invitrogen (Carlsbad, CA, USA). Fetal calf serum (FCS) and other cell culture reagents, unless otherwise indicated, were from Gibco (Invitrogen).

2.2. Cell Culture. Primary mouse keratinocytes were prepared from newborn mice, as previously described [12], and cultured at $37^{\circ} \mathrm{C}$ in an atmosphere of $5 \% \mathrm{CO}_{2}$ in Cnt07 medium with appropriate supplements (Cellntec, Berne, Switzerland).

2.3. Cell Proliferation (MTS/PMS) and BrdU Incorporation Assays. Cell proliferation was assayed using the MTS/PMS 
method. Briefly, cells $\left(1 \times 10^{3} /\right.$ well $)$ were plated in 96-well culture plates (Nunclon; Nunc, Roskide, Denmark). After overnight incubation, cells were treated in the absence or presence of $\mathrm{LiCl}$ and AS-IV. Each concentration was regarded as a single treatment group, while the control group only contained DMSO. Each group contained six replicate wells. After culture plates were incubated for $0,24,48$, or $72 \mathrm{~h}$, $100 \mu \mathrm{L}$ of MTS/PMS working solution was added to each well, and the keratinocytes were then incubated continuously for another $4 \mathrm{~h}$. The absorbance ( $A$ value) of each well was measured using a spectrophotometer (Beckman Coulter; Miami, FL, USA) at $490 \mathrm{~nm}$. The effect of AS-IV on the cell growth inhibitory rate in keratinocytes was calculated according to the following formula: $\%$ inhibitory rate $=\left[\mathrm{A}_{490}\right.$ value of treated group $] /\left[\left(A_{490}\right.\right.$ value of control group $) \times$ $(100 \%)]$. The $50 \%$ inhibitory concentration $\left(\mathrm{IC}_{50}\right)$ was determined from dose-response data from at least three independent experiments. Cell number and cell viability were determined daily using a Coulter Counter (Beckman Coulter-Z2) and the trypan blue dye exclusion test. For the 5-bromo-2'-deoxyuridine (BrdU) incorporation assay, cells were seeded and serum starved as above. After treatment with $\mathrm{PBS}$ or $\mathrm{LiCl}$ at different concentrations for $12 \mathrm{~h}$ in $10 \%$ FBS-containing media, cells were incubated with BrdU for an additional $2 \mathrm{~h}$. BrdU-labeled cells were detected using an enzyme-linked immunosorbent assay- (ELISA-) based colormeric kit (BD Biosciences; San Diego, CA, USA) according to the protocol provided by the manufacturer.

2.4. Western Blot Analysis. Lysates from cultured cells were prepared as previously described [13]. Whole cell protein extracts were resolved by SDS-PAGE and electrotransferred to membranes for specific antibody detection as previously described [14].

2.5. In Vitro Scratch Assay. When mouse keratinocytes reached $100 \%$ confluency, cells were transferred to basal KBM medium (Life Technologies, Inc., Grand Island, NY, USA) and incubated for $24 \mathrm{~h}$. Cells were then treated with $8 \mu \mathrm{g} / \mathrm{mL}$ mitomycin (ICN, Irvine, CA, USA) for $1 \mathrm{~h}$ and then washed with basal media. $\mathrm{LiCl}$, an inhibitor of glycogen synthase kinase 3 (GSK3), was applied to activate Wnt signaling. Since $\mathrm{LiCl}$ can also efficiently block EGF-stimulated migration, EGF-induced cell migration was used as a positive control. Scratches were performed in treated cell cultures as previously described, and cultures were photographed. Then, mixtures of $20 \mu \mathrm{mol} / \mathrm{L} \mathrm{LiCl}$ with or without $25 \mathrm{ng} / \mathrm{mL}$ EGF and $80 \mu \mathrm{g} / \mathrm{mL}$ AS-IV were added to the cultures and incubated for $24 \mathrm{~h}, 48 \mathrm{~h}$, or $72 \mathrm{~h}$. The cells were rephotographed, and comparisons to the pre-treatment images were used to quantitatively determine the extent of cell migration as previously described. Briefly, the distance covered by a cell moving into the scratch wound area was measured. Thirty measurements were taken for each experimental condition. Three images were analyzed per condition and per time point.

2.6. Flow Cytometry for Cell Cycle Analysis. Cells were plated at a density of $1.5 \times 10^{6}$ cells per $6 \mathrm{~cm}$ diameter dish and allowed to grow for $24 \mathrm{~h}$, after which the medium was changed to serum-free medium. After 16-18 h of starvation, cells are synchronized in the $G_{0}$ phase of the cell cycle. Different experimental reagents were then added to the serumfree medium and incubated for the indicated times. Cells $\left(1 \times 10^{6}\right)$ were harvested by trypsinization, washed twice in cold PBS, and fixed in 70\% alcohol for $30 \mathrm{~min}$ on ice. After washing in cold PBS three times, cells were resuspended in $1 \mathrm{~mL}$ Krishan staining solution [15] and left overnight at $4^{\circ} \mathrm{C}$. The next day, cells were filtered through a 96-micron pore size nylon mesh, and a total of 10000 stained nuclei were analyzed with a flow cytometer (BD Biosciences). DNA histograms were prepared using the accompanying ModFit analysis program (BD Biosciences), which plots and statistically fits the fractions of cells in the $G_{0}-G_{1}, S$, and $G_{2}-M$ phases. Each condition was repeated in triplicate.

2.7. Immunofluorescence Staining. Cells were cultured on 8-well chamber slides (Thermo Fisher Scientific, Waltham, MA, USA) and treated with different concentrations of ASIV for $24 \mathrm{~h}$. Cells were then fixed with $4 \%$ paraformaldehyde, permeabilized with $0.3 \%$ Triton X-100, and digested in pepsin solution (Lab Vision, Thermo Fisher Scientific). Nonspecific binding in crude protein extracts was blocked by incubating cells in $10 \%$ normal goat serum plus $0.1 \%$ NP40 for $1 \mathrm{~h}$. Detection of specific proteins was carried out by incubating with primary antibodies overnight. Alexa Fluor 488- or 594-conjugated secondary antibodies were used for immunofluorescence staining, and images were obtained with a Leica SP2 confocal microscope (Deerfield, IL, USA).

2.8. Statistical Analysis. Data are presented as the mean \pm SD of at least three independent experiments, unless designated otherwise. Statistical analysis was carried out using Student's $t$-Test, and a value of $P<0.05$ was considered to be significant.

\section{Results}

3.1. AS-IV Attenuates LiCl-Induced Inhibition of Keratinoctye Growth. To investigate the normal function of the Wnt signaling pathway in keratinocytes, we used $\mathrm{LiCl}$ to activate the $\mathrm{Wnt} / \beta$-catenin signaling pathway. The effect of $\mathrm{LiCl}$ on keratinocyte proliferation was examined by the MTS/ PMS assay and measurement of BrdU incorporation into DNA during DNA synthesis. As shown in Figure 2(a), keratinocytes were treated with different concentrations $(0$ $40.0 \mathrm{mM} / \mathrm{L}$ ) of $\mathrm{LiCl}$ for 24,48 , and $72 \mathrm{~h}$. Controls were subconfluent and synchronous keratinocytes were treated with DMSO solvent alone for the indicated times. Compared to the control group, LiCl-treated keratinocytes exhibited consistent growth retardation. The half maximal (50\%) inhibitory concentration $\left(\mathrm{IC}_{50}\right.$ ) values (Figure $2(\mathrm{a})$, dotted line) of growth achieved after LiCl-treatment for 24, 48, and $72 \mathrm{~h}$ were $25.85 \pm 5.03,16.16 \pm 0.95$, and $12.35 \pm 1.38 \mathrm{mM}$, respectively. Lower concentrations of $\mathrm{LiCl}(<5 \mathrm{mM})$ did not inhibit keratinocyte growth. Higher concentrations of $\mathrm{LiCl}$ 


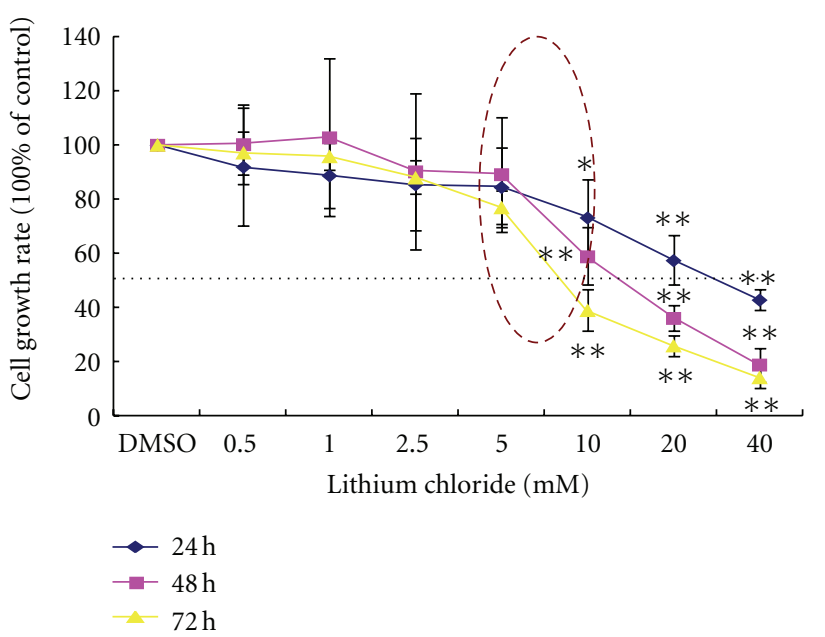

(a)

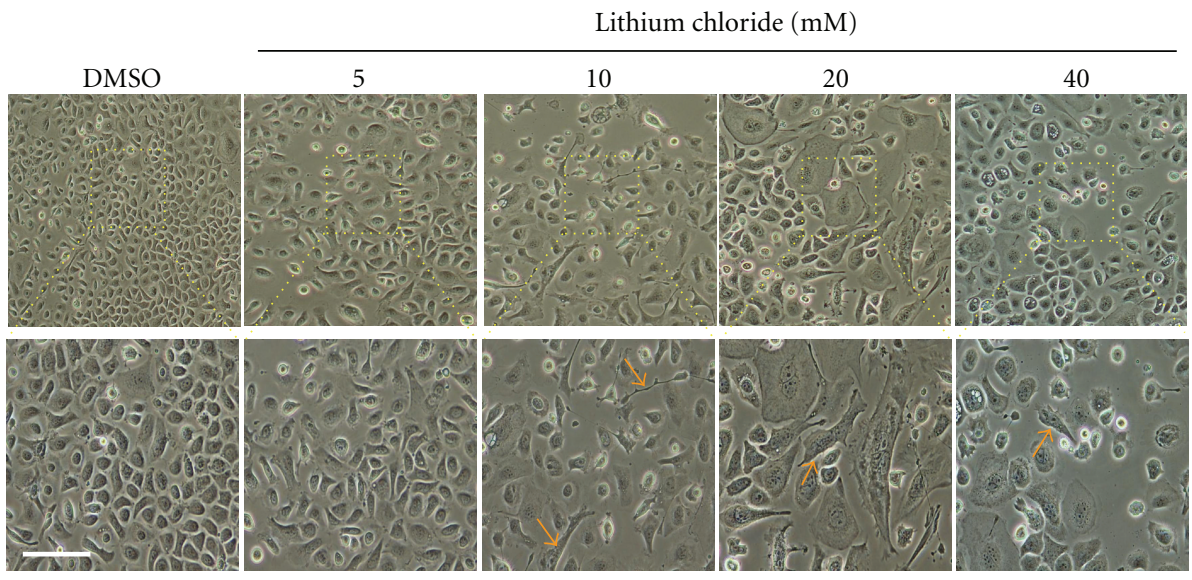

(b)

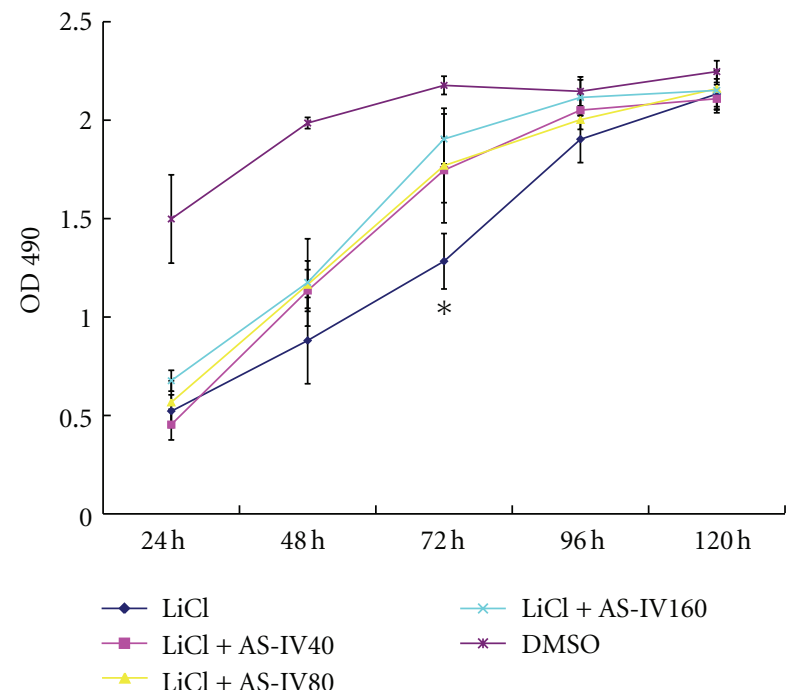

(c)

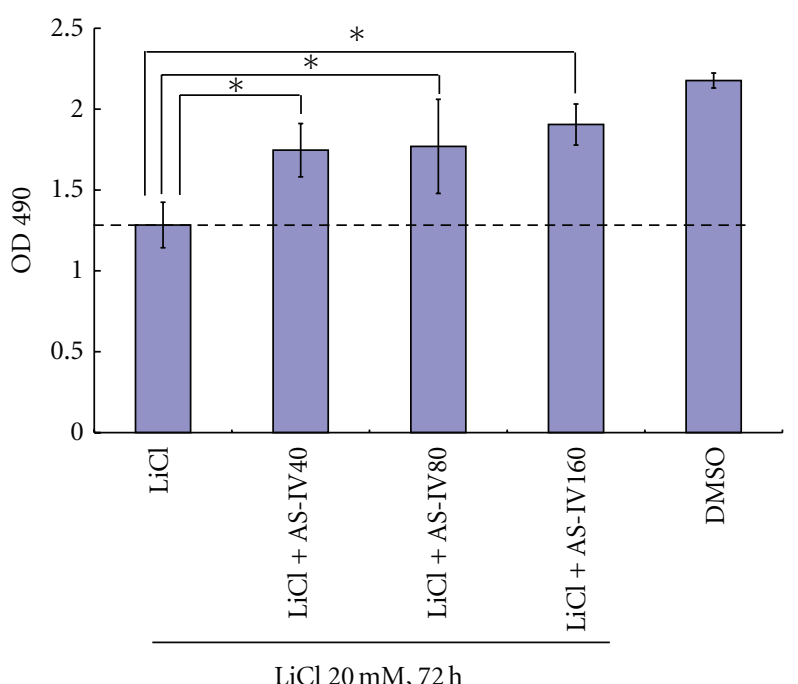

(d)

FIGURE 2: Cell proliferation of keratinocytes in response to $\mathrm{LiCl}$ and $\mathrm{AS}-\mathrm{IV}$ treatment. (a) LiCl inhibits proliferation of mouse keratinocytes, as evidenced by the MTS/PMS assay. Data are expressed as a percentage of the control (100\%) and represent the mean \pm SD of three experiments. ${ }^{*} P<0.05,{ }^{*} P<0.01$. (b) LiCl induced a senescent-like morphology in live keratinocytes, as evidenced by phase-contrast microscopy. (c) Growth curve of keratinocytes in response to LiCl and AS-IV treatments. (d) OD at 490 nm of keratinocytes treated with or without $\mathrm{LiCl}$ and AS-IV for $72 \mathrm{~h}$. Scale bar $=100 \mu \mathrm{m}$. 


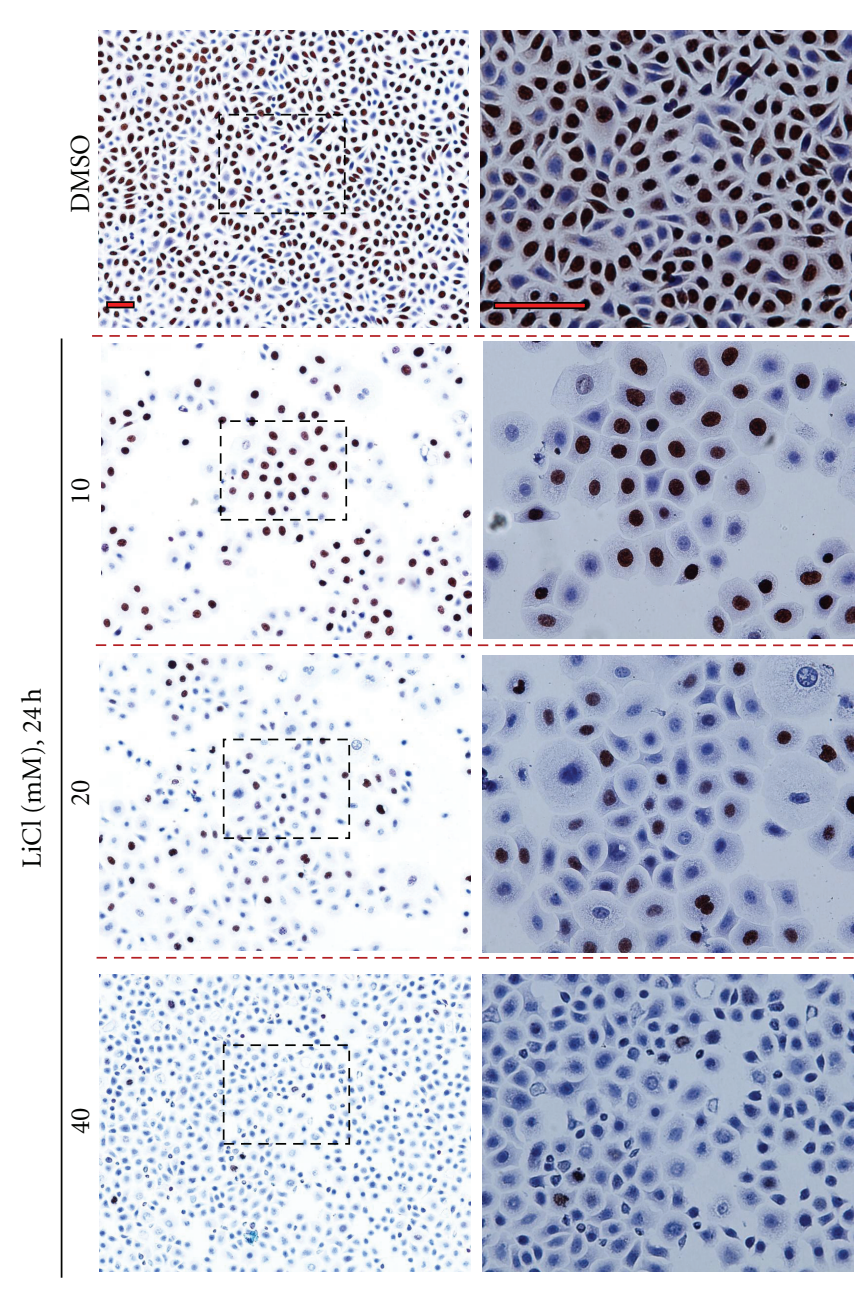

(a)

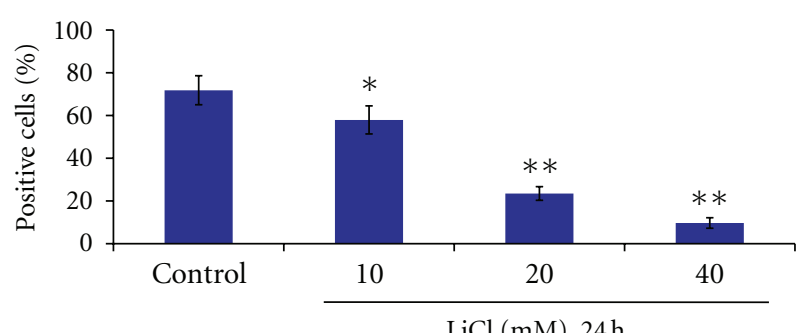

(b)

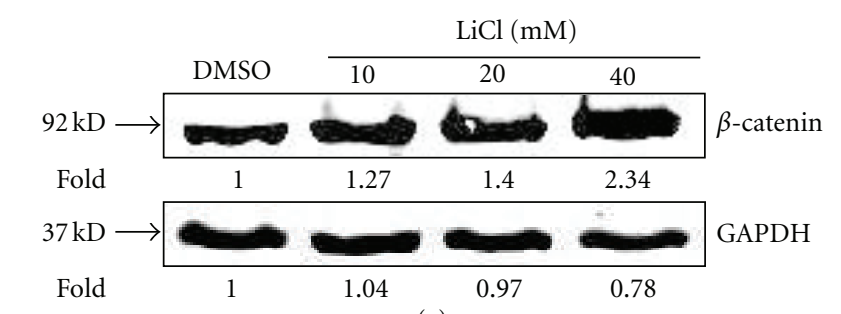

(c)

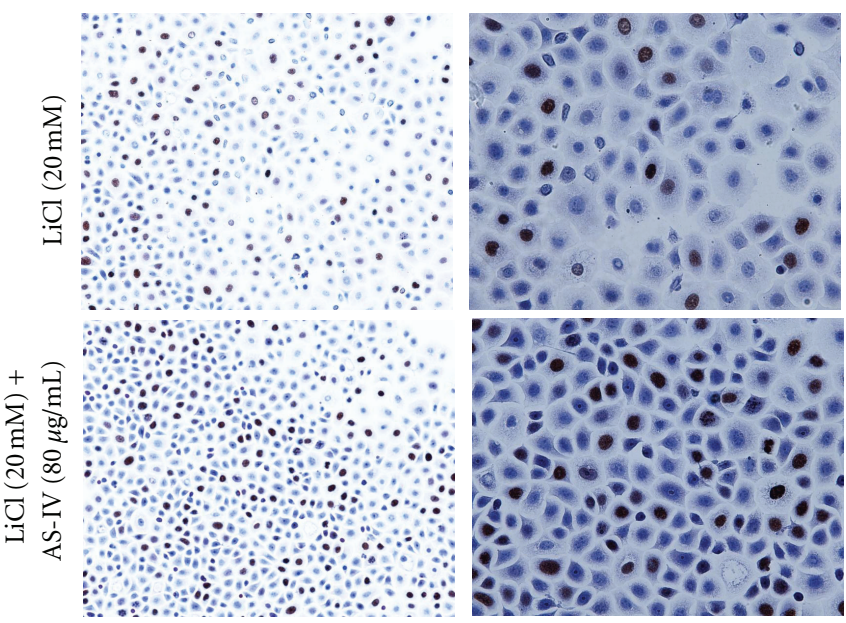

(d)

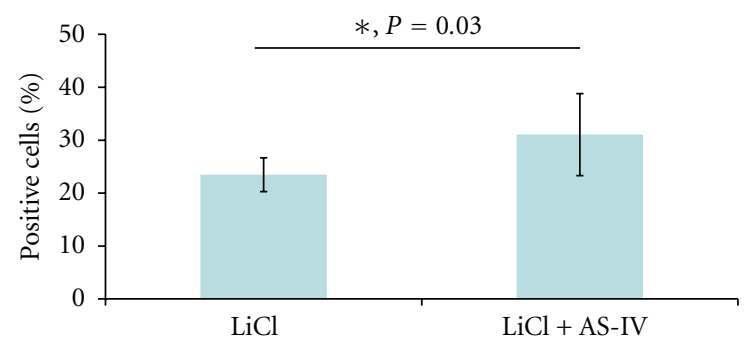

(e)

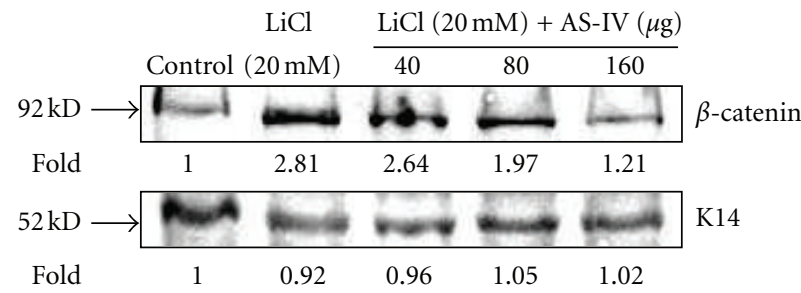

(f)

FIGURE 3: BrdU staining of cells treated with $\mathrm{LiCl}$ in the absence of presence of AS-IV. (a) LiCl treatment produced a concentrationdependent decrease in BrdU-positive cells compared to control cells. (b) Histograms represent the mean \pm SD of the percent of BrdU-positive cells treated with different concentrations of LiCl. (c) Changes in $\beta$-catenin protein expression in response to LiCl. (d, e, f) Comparison of the effects of $\mathrm{LiCl} \pm \mathrm{AS}$-IV on cell proliferation, by detection of BrdU incorporation and $\beta$-catenin protein expression. AS-IV resolved LiClinduced inhibition of cell proliferation and downregulation of $\beta$-catenin. ${ }^{*} P<0.05$. Expression of K14 and GAPDH were detected as protein loading controls Scale bar $=100 \mu \mathrm{m}$.

( $>5 \mathrm{mM}$ ) produced significant and dose-dependent inhibition of keratinocyte proliferation (Figure 2(a), circle). The BrdU incorporation assay also revealed a concentrationdependent decrease in BrdU-positive cells in response to different dosages of $\mathrm{LiCl}$. As shown in Figure 3(a), the amount of BrdU-positive cells following LiCl-treatment of $10 \mathrm{mM}$
(57.91 $\pm 6.57 \%), 20 \mathrm{mM}(23.48 \pm 3.19 \%)$, and $40 \mathrm{mM}$ $(9.67 \pm 2.45 \%)$ was significantly less than those in the DMSO-treatment control group $(71.81 \pm 6.79 \%$; all $P<$ $0.01)$. Cell viability was unaffected by LiCl-treatment at all doses (Figure 4(c)). These data unambiguously confirm that $\mathrm{LiCl}$ is able to exert potent growth inhibitory effects on 

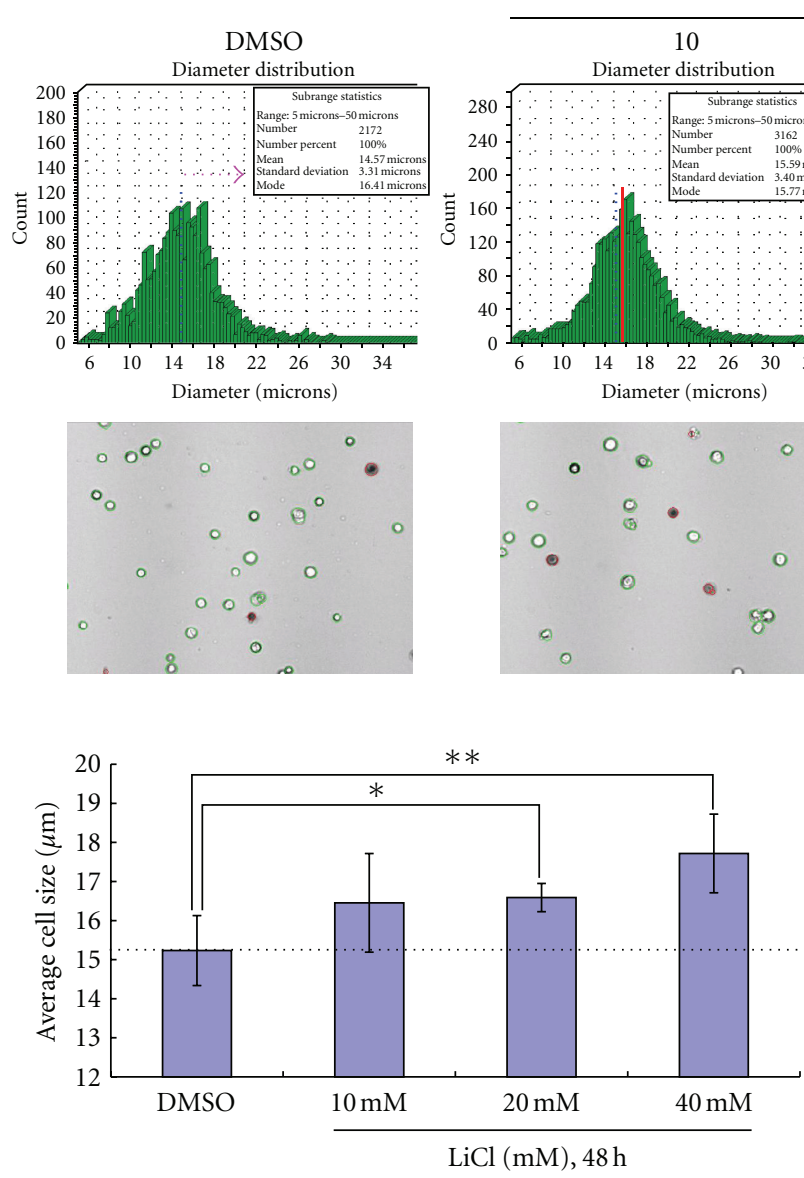

(b)

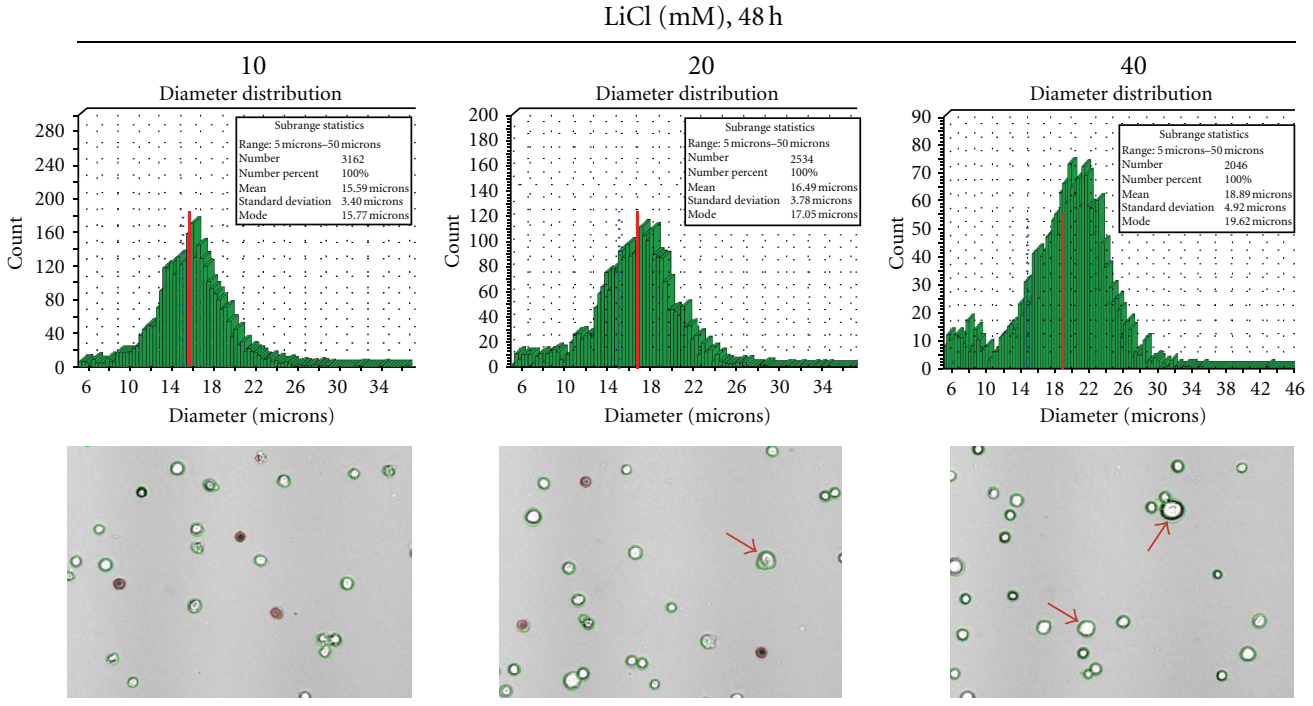

(a)

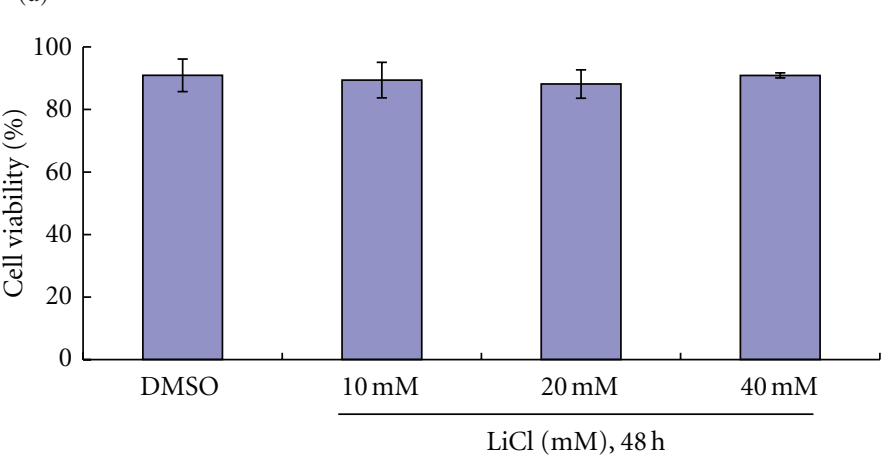

(c)

FIGURE 4: LiCl affects keratinocyte morphology but not cell viability. Treatment with $20 \mathrm{mM}$ and $40 \mathrm{mM}$ LiCl caused cell size to enlarge (a, red arrow). (b) Average cell size from three experiments. (c) LiCl treatment had no effect on keratinocyte viability, as evidenced by the cell viability assay.

keratinocytes in a concentration- and time-dependent manner. These results also indicate that LiCl-treatment inhibits keratinocyte proliferation without affecting their viability.

To investigate the function of AS-IV in keratinocytes overexpressing $\beta$-catenin, we incubated the cells with ASIV and $\mathrm{LiCl}$ for $72 \mathrm{~h}$. As shown in Figures 2(c) and 2(d), AS-IV treatment attenuated LiCl-induced inhibition of cell proliferation, as evidenced by the fact that optical density (OD) at $490 \mathrm{~nm}$ was significantly higher in the $\mathrm{LiCl}$ group than in the DMSO control group $(P<0.05)$. Similarly, the BrdU assay showed that AS-IV treatment was able to enhance the percentage of positive cells (from $23.48 \%$ to $31.05 \%$; Figure $3(\mathrm{e})$ ), suggesting that AS-IV was able to promote DNA synthesis.

\subsection{LiCl Induces Senescence-Like Changes in Keratinocytes.} $\mathrm{LiCl}$ treatment also led to obvious morphological changes in keratinocytes, including increased size, spreading, and flattened appearance. There were no rounded cells, characteristic of apoptosis, observed in LiCl-treated cultures (Figure 2(b)). Using the cell viability assay, we measured the change in diameter of keratinocytes in response to exposure to different doses of $\mathrm{LiCl}$ (from $10 \mathrm{mM}$ to $40 \mathrm{mM}$ ) for $48 \mathrm{~h}$. As shown in Figure 4, $\mathrm{LiCl}$ treatment at doses of $20 \mathrm{mM}$ and $40 \mathrm{mM}$ resulted in an enlarged cell size (Figure 4(a), red arrow), which indicated that high concentrations of $\mathrm{LiCl}$ may change keratinocyte morphology. The average diameters of LiCl-treated keratinocytes were greater $(10 \mathrm{mM}, 16.45 \pm$ $1.36 \mu \mathrm{m} ; 20 \mathrm{mM}, 16.59 \pm 0.36 \mu \mathrm{m} ; 40 \mathrm{mM}, 17.72 \pm 1.01 \mu \mathrm{m})$ than that in the control group $(15.23 \pm 0.97 \mu \mathrm{m})$.

\subsection{AS-IV Attenuates LiCl-Induced S Phase Cell Cycle Arrest in} Keratinocytes. LiCl-induced inhibition of growth may result from cell cycle effects. Thus, the cell cycle distribution of LiCl-treated and control cells was determined by measuring the DNA content of Krishan-stained cells using fluorescenceactivated cell sorting. As shown in Figure 5, LiCl-treated cells exhibited a higher proportion of cells in the $S$ phase than control cells. Histograms were generated to visualize the percent of cell cycle distributions produced by different $\mathrm{LiCl}$ concentrations (Figure 5(b)) and different exposure times (Figure 5(c)). Interestingly, when LiCl-treated cells were 

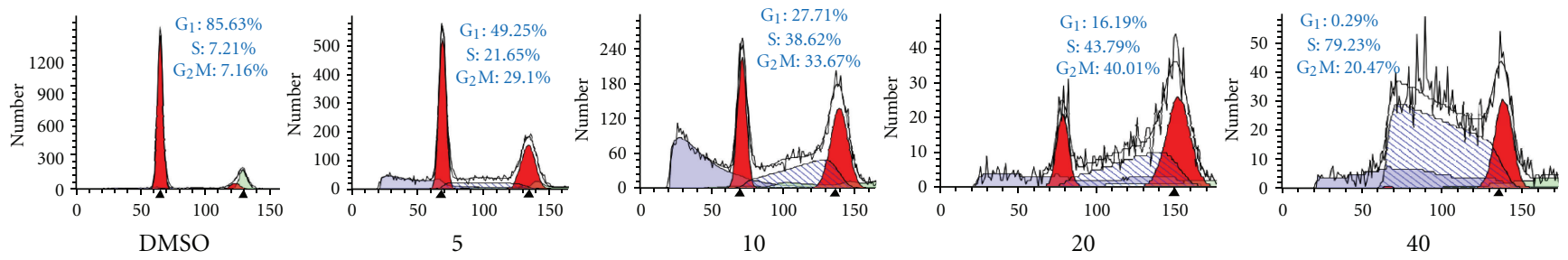

$\mathrm{LiCl}(\mathrm{mmol} / \mathrm{L}), 24 \mathrm{~h}$

(a)

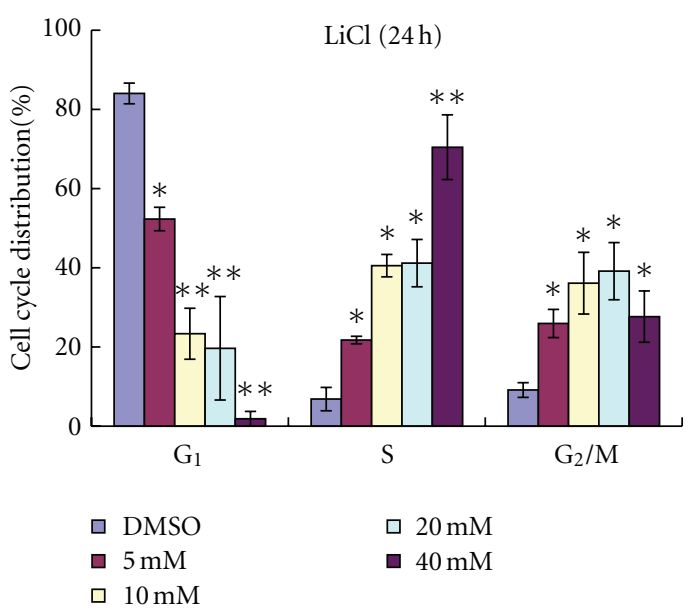

(b)

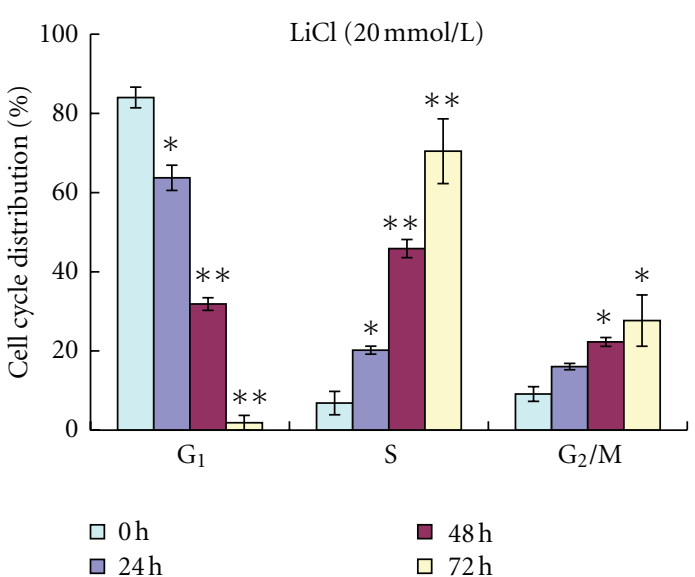

(c)

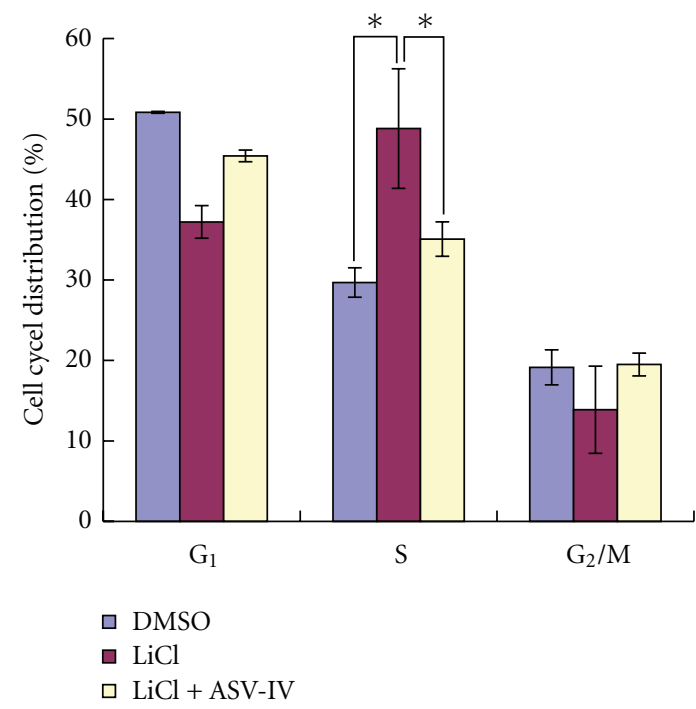

(d)

Figure 5: LiCl induces S phase arrest in keratinocytes. (a) Keratinocytes were exposed to various concentrations of LiCl for $24 \mathrm{~h}$. (b) Keratinocytes were exposed to $20 \mathrm{mM} \mathrm{LiCl}$ for $24 \mathrm{~h}, 48 \mathrm{~h}$, and $72 \mathrm{~h}$. (c) Histogram showing the average amounts of cells in various cell cycle stages from three experiments following a $24 \mathrm{~h}$ exposure to different $\mathrm{LiCl}$ concentrations. (d) Histogram showing the average distribution of cells in various cell cycle stages from three experiments with $\mathrm{LiCl} \pm \mathrm{AS}-\mathrm{IV}$, and $\mathrm{LiCl}+\mathrm{EGF}$ treatments.

exposed to AS-IV, there was remarkable attenuation of induced cell cycle arrest in the S phase. Specifically, the percentage of $\mathrm{S}$ phase cells in LiCl-treated keratinocytes cultures went from $48.81 \pm 7.43$ to $35.28 \pm 2.14$ upon AS-IV exposure $(P<0.05)$.
3.4. AS-IV Attenuates LiCl-Induced Overexpression of $\beta$-Catenin in Keratinocytes. We investigated the effect of AS-IV on $\beta$-Catenin expression in primary keratinocytes using two standard assays, namely immunofluorescence staining and Western blot analysis. As expected, keratinocytes incubated 

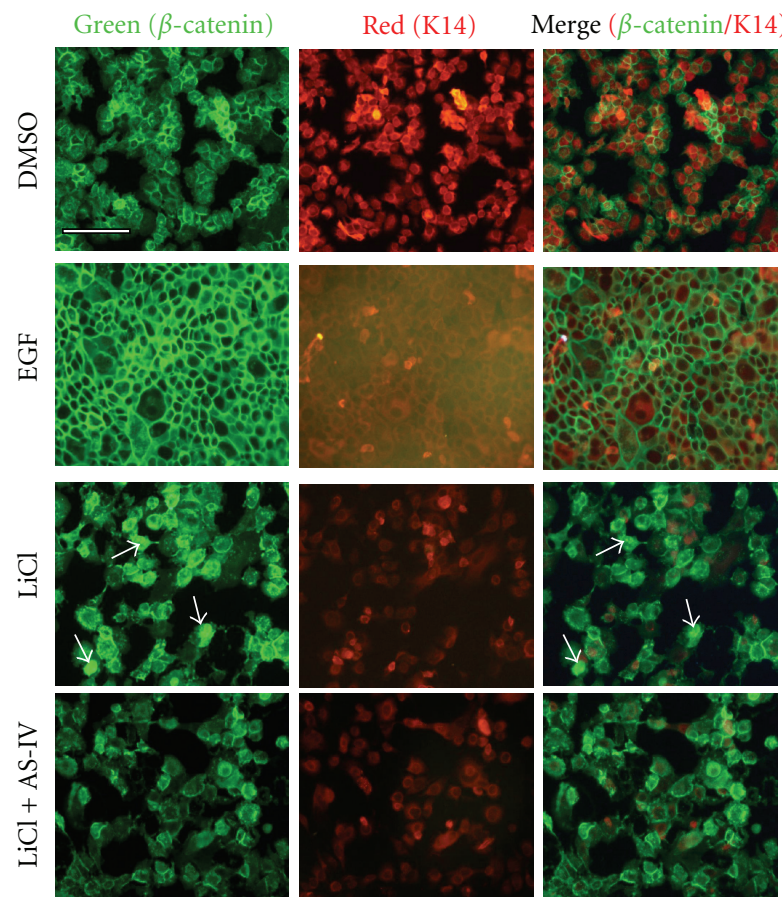

(a)

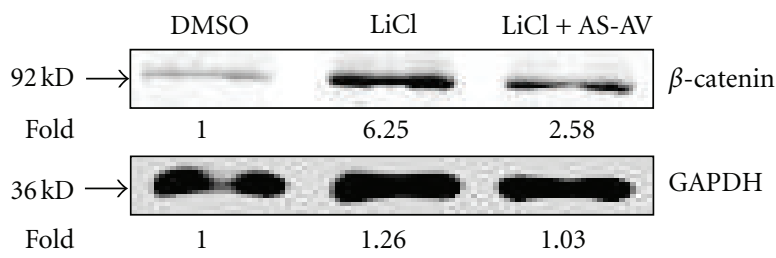

(b)

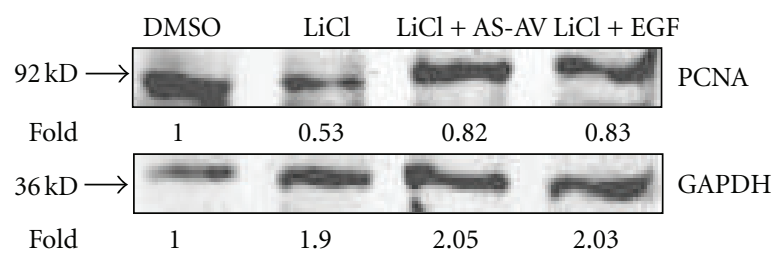

(c)

FIGURE 6: $\beta$-catenin is differentially regulated by $\mathrm{LiCl}$ and AS-IV. Stabilization of $\beta$-catenin in keratinocytes was followed by immunofluorescence staining with a $\beta$-catenin-specific antibody (a) and Western blot analysis (b). (a) DMSO (negative control) and EGF (positive control) treated keratinocytes exhibited normal $\beta$-catenin membrane expression. The LiCl-treated group showed stabilized $\beta$-catenin, which was downregulated following AS-IV treatment. (b) GAPDH protein expression was used as the protein loading control. (c) Western blot analysis revealed that PCNA expression, which is related to cell proliferation, was downregulated $50 \%$ by LiCl compared to the control cells, and upregulated to $80 \%$ by AS-IV. GAPDH expression was used as a protein loading control. Asterisks indicate statistically significant differences between control and LiCl-treated cells. The scale bar in the first panel of (a) represents $100 \mu \mathrm{m}$, and is applicable to both sections.

with EGF showed normal $\beta$-catenin membrane expression, but those treated with $\mathrm{LiCl}$ exhibited prominent nuclear $\beta$-catenin staining. LiCl-induced nuclear $\beta$-catenin was attenuated by AS-IV exposure, as evidenced by remarkably less $\beta$-catenin nuclear staining (Figure 6(a)). Similarly, Western blot analysis indicated that LiCl-treated keratinocytes expressed over 5 -fold more $\beta$-catenin than the control cells. In addition, AS-IV exposure of LiCl-treated cells led to nearly 3 -fold less $\beta$-catenin that that in the control group (Figure 6(b)) and additionally, PCNA, which indicating the cell proliferation, was downregulated $50 \%$ by $\mathrm{LiCl}$ compared with DMSO control, and upregulated to $80 \%$ by AS-IV (Figure 6(c)).

\subsection{AS-IV Attenuates LiCl-Induced Migration Inhibition of} Keratinocytes. To test if $\mathrm{LiCl}$-induced overexpression of $\beta$ catenin can affect keratinocyte migration during wound healing, we used the in vitro wound scratch assay. Keratinocytes were incubated with $\mathrm{LiCl}, \mathrm{LiCl}$ and EGF (positive control), and/or AS-IV for $72 \mathrm{~h}$. Keratinocyte migration into the scratch area was observed and the distance was quantified. As shown in Figure 7, $\mathrm{LiCl}$ treatment inhibited keratinocyte migration by almost $80 \%$, whereas $\mathrm{LiCl}$ and AS-IV promoted migration by $60 \%$, presumably via downregulation of activated $\beta$-catenin.

3.6. AS-IV Attenuates LiCl-Induced Downregulation of $\beta$ Tubulin. Tubulin protein is a key mediator of cell migration [16]. To determine whether $\mathrm{LiCl}$ treatment affected $\beta$ tubulin expression, we incubated primary keratinocytes with $\mathrm{LiCl}$ alone or with AS-IV. Changes in $\beta$-tubulin expression levels were evaluated by immunofluoresence following staining of treated cells with a $\beta$-tubulin-specific antibody (Figure $8(\mathrm{a})$ ), and by immunoblotting (Figure $8(\mathrm{c})$ ). $\beta$-tubulin was 


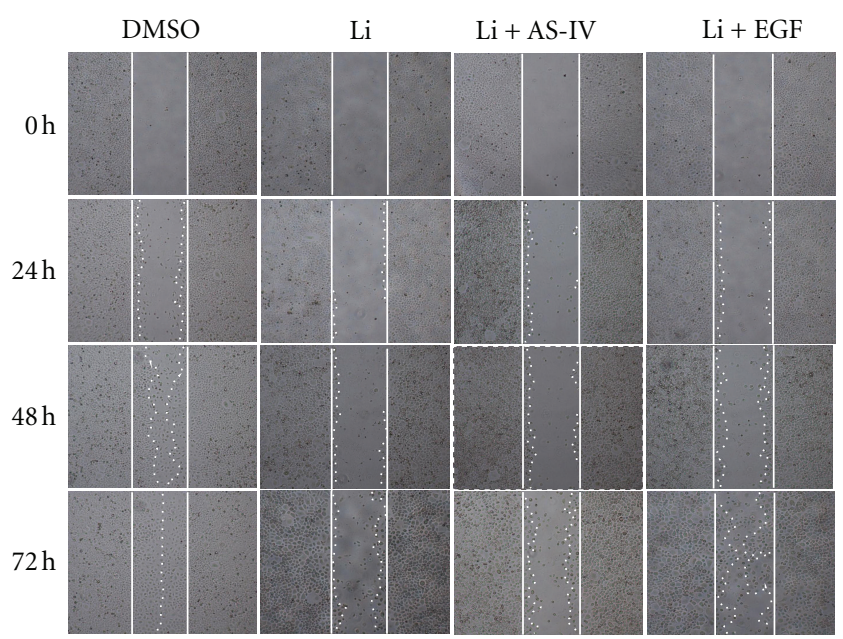

(a)

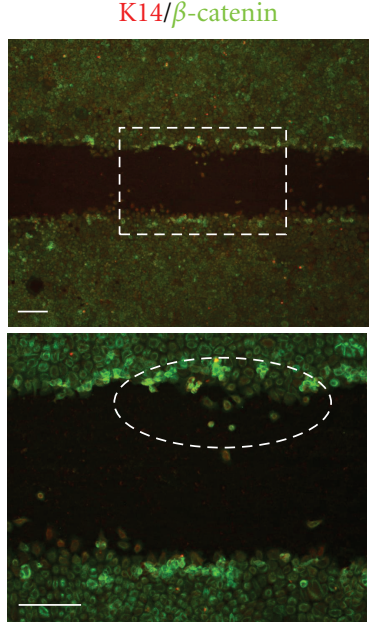

$\mathrm{LiCl}(20 \mathrm{mmol} / \mathrm{L}), 24 \mathrm{~h}$

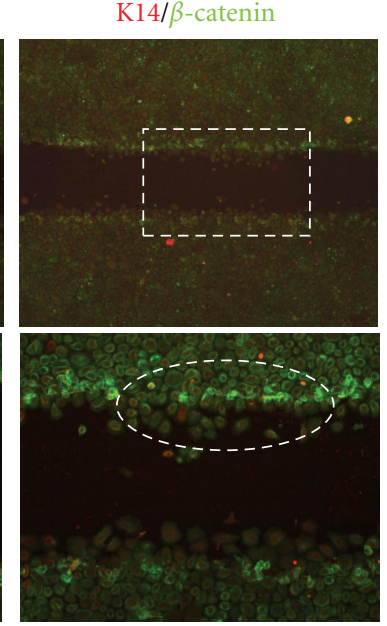

$\mathrm{LiCl}(20 \mathrm{mmol} / \mathrm{L})+$ AS-IV $(80 \mu \mathrm{g} / \mathrm{mL}), 24 \mathrm{~h}$

(b)

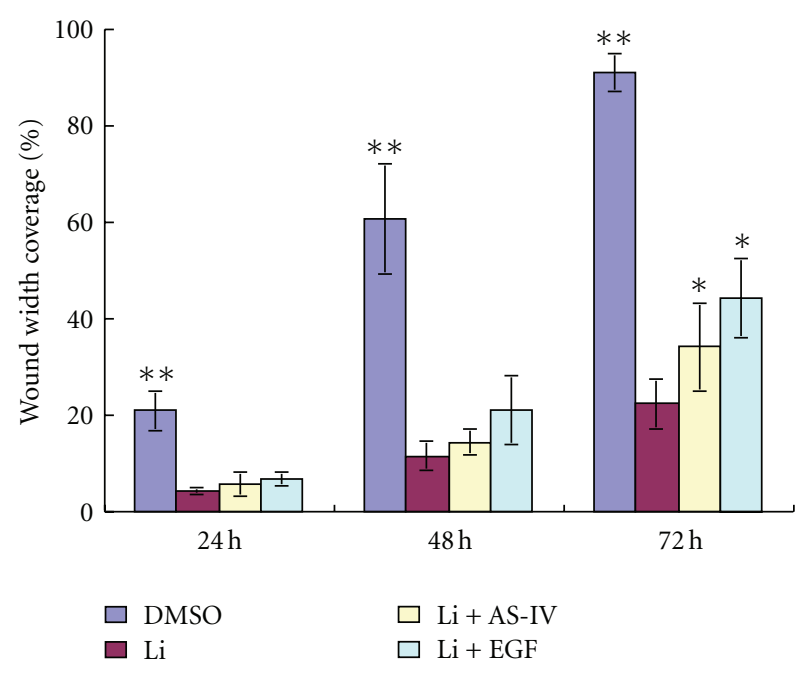

(c)

FIgURE 7: AS-IV attenuates LiCl-induced inhibition of keratinocyte migration. (a) Mouse primary keratinocytes with LiCl-induced activation of $\beta$-catenin were used in the scratch assay. LiCl inhibited keratinocyte migration compared to untreated cells. Inhibition was prominent at $48 \mathrm{~h}$ and was sustained through $72 \mathrm{~h}\left({ }^{* *} P<0.01\right)$. EGF (positive control) stimulated migration was significant after $72 \mathrm{~h}$, as evidenced by the nearly closed wound. AS-IV attenuated the LiCl-induced keratinocyte migration inhibition effect, as evidenced by the difference in wound closure after $72 \mathrm{~h}\left({ }^{*} \mathrm{P}<0.05\right.$, compared with LiCl-treated group). Straight lines demarcate the initial wound area, and dotted lines indicate the migrating front of cells. (b) $\beta$-catenin was upregulated at the scratch wound edge. Insets show enlarged images of the dotted rectangle. The white circle indicates the keratinocytes starting to migrate from the nonnuclear $\beta$-catenin-positive cell. Scale bar $=$ $100 \mu \mathrm{m}$. (c) Histograms showing the average coverage of scratch wounds widths as percentages of the baseline wound width at time of scratch (0) and $24 \mathrm{~h}, 48 \mathrm{~h}$, and $72 \mathrm{~h}$ after LiCl, $\mathrm{LiCl}+\mathrm{AS}-\mathrm{IV}$, and $\mathrm{LiCl}+\mathrm{EGF}$ treatments. ${ }^{*} P<0.05,{ }^{* *} P<0.01$. Scale bar $=100 \mu \mathrm{m}$.

expressed in most of the untreated primary keratinocytes, but LiCl-treatment reduced $\beta$-tubulin expression. As shown in Figure 8(b), $\beta$-tubulin was expressed in only $15 \%$ of LiCltreated cells but was expressed in $27 \%$ of cells treated with $\mathrm{LiCl}$ and AS-IV. In the DMSO-treated control cultures, $80 \%$ of cells expressed $\beta$-tubulin. Together, our findings indicate that $\mathrm{LiCl}$ is able to cause downregulation of $\beta$-tubulin, which was resolved, at least in part, by treatment with AS-IV. Thus, overexpression of $\beta$-catenin during the wound healing process may impair healing by reducing $\beta$-tubulin expression, and subsequently inhibiting keratinocyte migration. Since AS-IV can attenuate LiCl-induced downregulation of $\beta$ tubulin, it may represent a promising therapeutic agent for improving migration and promoting wound healing.

\section{Discussion}

In developed countries, 0.2 to $1 \%$ of the population is affected by chronic venous ulcers [17]. In China, it has been reported that approximately $1.5 \%-3.0 \%$ of surgical 


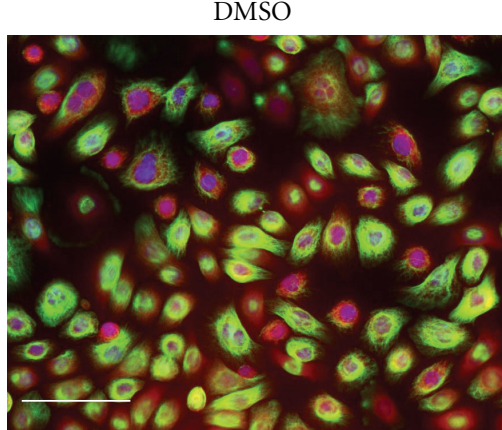

K14/ß-tubulin/DAPI

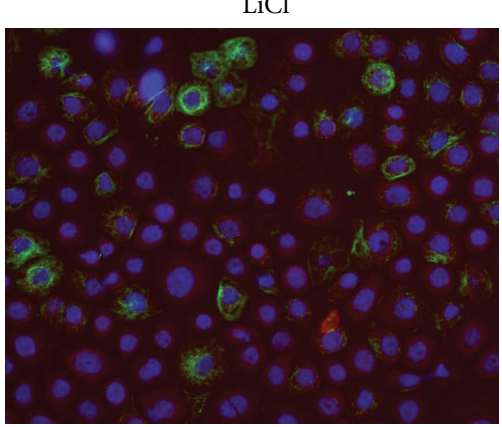

K14/ß-tubulin/DAPI

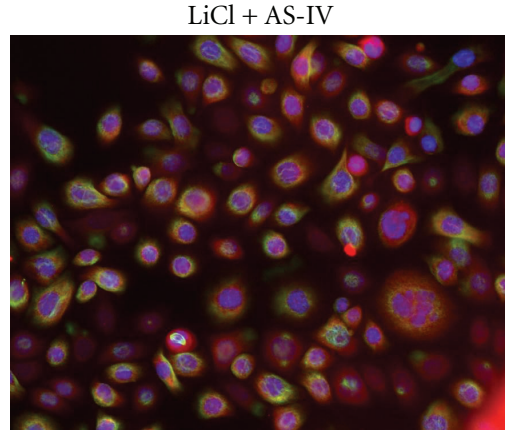

K14/ $\beta$-tubulin/DAPI

(a)

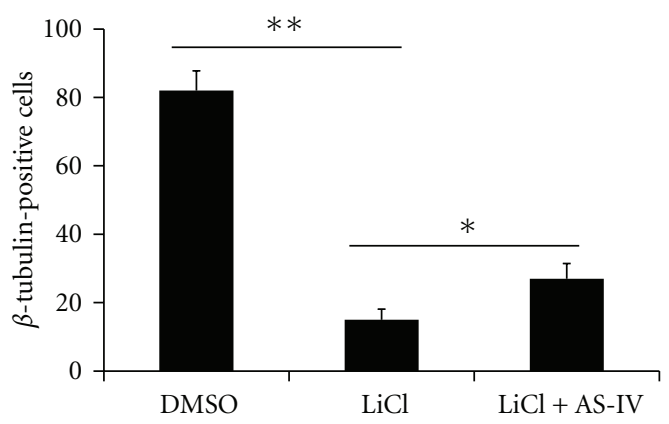

(b)

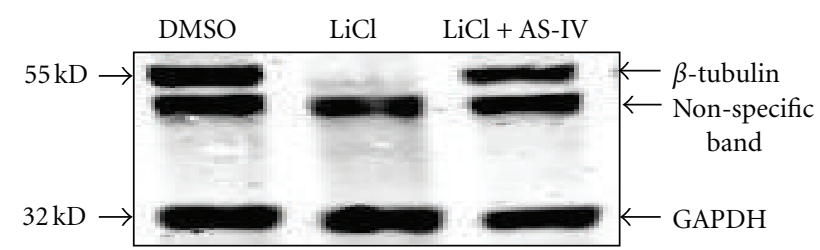

(c)

Figure 8: AS-IV attenuates LiCl-induced $\beta$-tubulin downregulation. Keratinocytes were treated with $\mathrm{LiCl}(20 \mathrm{mM})$ and $\mathrm{LiCl}(20 \mathrm{mM})+$ AS-IV $(80 \mu \mathrm{g} / \mathrm{mL})$ for $24 \mathrm{~h}$, and $\beta$-tubulin was determined by immunofluorescence (a, merged images of K14/ $\beta$-tubulin/DAPI were shown) and immunoblotting ((c), GAPDH protein expression was used as the protein loading control). (b) Cell numbers of $\beta$-tubulin-positive keratinocytes per 100 total cells are presented. AS-IV significantly attenuated LiCl-induced $\beta$-tubulin downregulation. ${ }^{*} P<0.05,{ }^{* *} P<0.01$. Scale bar $=100 \mu \mathrm{m}$.

inpatients are hospitalized for chronic refractory wounds. Nonhealing chronic wounds not only decrease the quality of life of the sufferer and increase risk of further infection and death, but also represent a significant economic burden on the healthcare system. The experiments described in the present study show that AS-IV is able to repair chronic cutanous wounds through regulation of cell migration and cell proliferation.

Among the many biological molecules known to influence wound healing, Wnt signaling is believed to be crucial, as it mediates skin development throughout life and can exert both positive and negative effects on the wound healing process. $\mathrm{LiCl}$ is a well-characterized inhibitor of GSK3, and as such can effectively activate Wnt signaling in vitro [10]. Numerous studies have shown that $\mathrm{LiCl}$ can elicit remarkably various effects on different cell types. For instance, $\mathrm{LiCl}$ was shown to stimulate proliferation of cultured erythrocytes via activation of the $\mathrm{Wnt} / \beta$-catenin signaling pathway [18]. In addition, LiCl-stimulated proliferation of MCF-7 human breast cancer cells and caused a remarkable change in the expression of phosphoinositide metabolites [19]. In contrast, administration of $\mathrm{LiCl}$ suppressed prostate cancer cell proliferation by disrupting the E2F-DNA interaction and subsequent E2F-mediated gene expression [20]. $\mathrm{LiCl}$ also inhibited proliferation of the human esophageal cancer cell line, Eca-109, by inducing G2/M cell cycle arrest [21]. Mao et al. reported that $\mathrm{LiCl}$ treatment induced cell cycle arrest in $\mathrm{G}_{2} / \mathrm{M}$ in primary bovine aortic endothelial cells without affecting cell viability [22]. These studies demonstrate that $\mathrm{LiCl}$ can mediate a wide variety of cellular functions depending on the context. Here, we demonstrate that $\mathrm{LiCl}$ can induce cell proliferation and migration inhibition and cause $S$ phase arrest in mouse primary keratinocytes (Figure 5).

The important role of Wnt signaling pathway activation in wound healing is well recognized [23, 24]. The Wnt signaling pathway is known to regulate a variety of cell functions, including cell fate, polarity, and differentiation, via the canonical or $\beta$-catenin stabilization pathway and/or the planar cell polarity or noncanonical pathway [25]. In addition, Wnt signaling was previously shown to mediate proliferation and migration of fibroblasts and keratinocytes [26]. Keratinocytes, the major cellular component of the epidermis, have several critical roles in the wound healing process. The keratinocytes that appear at the nonhealing edges of chronic wounds have been shown to overexpress $\beta$-catenin protein and are believed to differ from normal, healthy keratinocytes.

During the normal wound healing process, the reepithelialization stage involves covering the wound surface with a layer of epithelium, which involves differentiation, proliferation, and migration of epidermal keratinocytes. 
Research has shown that overexpression of $\beta$-catenin and c-myc contributes to impaired wound healing by inhibiting keratinocyte migration and altering their differentiation.

A previous study from our laboratory also indicated that a Chinese formula that included Radix astragali ingredients might be effective in regulating the Wnt signaling pathway [11]. However, the underlying mechanisms have remained ambiguous. AS-IV is the major phytochemical compound of the well-known Chinese herbal medicine Huangqi, which is extracted from the dried root of Radix astragali, and is a widely used herbal remedy in traditional Chinese medicine for the treatment of diabetes and inflammation [7]. Therefore, the goal of the present study was to determine the effect of AS-IV on keratinocyte proliferation and migration in wound healing.

In this report, we show that treatment of primary keratinocytes with $\mathrm{LiCl}$, an inhibitor of GSK-3 $\beta$ and an activator of the Wnt signaling pathway, induced stabilization and nuclear translocation of $\beta$-catenin associated with cell proliferation and migration inhibition. Moreover, $\mathrm{LiCl}$ treatment significantly induced cell cycle arrest in the S phase. MTS/PMS and cell viability assays showed that $\mathrm{LiCl}$ induced cell growth retardation without affecting cell viability; it appeared that this effect was a result of induction of a senescent-like phenotype. AS-IV treatment of LiCl-induced keratinocytes resulted in attenuated growth retardation and reduced amounts of cells in the $S$ phase. These new findings led us to hypothesize that $\beta$-catenin overexpression during impaired wound healing may account for the dysfunctional keratinocyte proliferation and migration.

In our study, the BrdU incorporation assay was used to determine DNA synthesis activity as an indirect method of evaluating cell proliferation. BrdU analysis showed that AS-IV treatment was able to increase the percentage of BrdU-positive cells (Figure 3(e)), indicating that AS-IV can effectively promote DNA synthesis activity in keratinocytes. Keratinocyte migration is essential for skin wound healing. Treatment with $\mathrm{LiCl}$ alone inhibited keratinocyte migration abilities in a wound scratch assay. Interestingly, $\beta$-catenin was upregulated at the scratch wound edge in LiCl-induced keratinocytes cultures. AS-IV effectively attenuated this LiClinduced migration inhibition effect (Figure 7). Moreover, we found that keratinocytes started to migrate from the nonnuclear $\beta$-catenin positive cell, indicating that the migration of $\beta$-catenin-positive cells is blocked and AS-IV treatment improves cell migration associated with $\beta$-catenin expression.

In summary, using $\mathrm{LiCl}$ as a tool to activate $\mathrm{Wnt} / \beta$ catenin signaling, we have shown the functional relevance of $\mathrm{Wnt} / \beta$-catenin signaling in keratinocyte proliferation and migration. Importantly, we have also provided evidence for the application of AS-IV in the treatment of wound healing and revealed its role in the wound healing reepithelialization stage. These AS-IV related discoveries provide novel insights into the molecular mechanisms underlying the significant regulation of the proliferative effects of AS-IV in keratinocytes, which can enhance epithelialization and healing of chronic wounds [27]. Future studies are needed to further elucidate the effect of AS-IV on other molecules and cells involved in wound healing, as this will help to advance the development of this drug for clinical application.

\section{Abbreviations}

$\begin{array}{ll}\text { AS-IV: } & \text { Astragaloside IV } \\ \text { LiCl: } & \text { Lithium chloride } \\ \text { DMSO: } & \text { Dimethyl sulfoxide } \\ \text { GSK-3: } & \text { Glycogen synthase kinase-3 } \\ \text { MTS/PMS: } & \text { 3-(4,5-dimethylthiazol-2-yl)-5-(3- } \\ & \text { carboxymethoxyphenyl)-2-(4-sulfophenyl)- } \\ & \text { 2H-tetrazolium, inner salt/phenazine } \\ & \text { ethosulfate } \\ \text { PI: } & \text { Propidium iodide } \\ \text { BrDU: } & \text { 5-bromo-2'-deoxyuridine } \\ \text { PBS: } & \text { Phosphate buffered saline } \\ \text { IC } 50: & \text { Half maximal (50\%) inhibitory concentration } \\ \text { PCNA: } & \text { Proliferating cell nuclear antigen. }\end{array}$

\section{Acknowledgments}

This study was supported by grants (nos. 81102596 and 30973751) from the National Science Foundation (NSFC) of China. It was also supported by grants (no. 11XD1404700) from Shanghai Science and Technology Committee, Innovation Program of Shanghai Municipal Education Commission (no. 12YZ067) and Innovative Research Team at the University of Shanghai Municipal Education Commission (phase II).

\section{References}

[1] X. J. Wang, G. Han, P. Owens, Y. Siddiqui, and A. G. Li, "Role of TGF $\beta$-mediated inflammation in cutaneous wound healing," Journal of Investigative Dermatology Symposium Proceedings, vol. 11, no. 1, pp. 112-117, 2006.

[2] P. R. Cavanagh, B. A. Lipsky, A. W. Bradbury, and G. Botek, “Treatment for diabetic foot ulcers," Lancet, vol. 366, no. 9498, pp. 1725-1735, 2005.

[3] A. J. Singer and R. A. F. Clark, "Cutaneous wound healing," New England Journal of Medicine, vol. 341, no. 10, pp. 738746, 1999.

[4] G. C. Gurtner, S. Werner, Y. Barrandon, and M. T. Longaker, "Wound repair and regeneration," Nature, vol. 453, no. 7193, pp. 314-321, 2008.

[5] S. Schreml, R. M. Szeimies, L. Prantl, M. Landthaler, and P. Babilas, "Wound healing in the 21st century," Journal of the American Academy of Dermatology, vol. 63, no. 5, pp. 866-881, 2010.

[6] C. Amendt, A. Mann, P. Schirmacher, and M. Blessing, "Resistance of keratinocytes to TGF $\beta$-mediated growth restriction and apoptosis induction accelerates re-epitheliazation in skin wounds," Journal of Cell Science, vol. 115, no. 10, pp. 21892198, 2002.

[7] W. J. Zhang, P. Hufnagl, B. R. Binder, and J. Wojta, "Antiinflammatory activity of astragaloside IV is mediated by inhibition of NF- $\kappa$ B activation and adhesion molecule expression," Thrombosis and Haemostasis, vol. 90, no. 5, pp. 904-914, 2003.

[8] J. Yu, Y. Zhang, S. Sun et al., "Inhibitory effects of astragaloside IV on diabetic peripheral neuropathy in rats," Canadian 
Journal of Physiology and Pharmacology, vol. 84, no. 6, pp. 579587, 2006.

[9] O. Stojadinovic, H. Brem, C. Vouthounis et al., "Molecular pathogenesis of chronic wounds: the role of $\beta$-catenin and cmyc in the inhibition of epithelialization and wound healing," American Journal of Pathology, vol. 167, no. 1, pp. 59-69, 2005.

[10] P. S. Klein and D. A. Melton, "A molecular mechanism for the effect of lithium on development," Proceedings of the National Academy of Sciences of the United States of America, vol. 93, no. 16, pp. 8455-8459, 1996.

[11] F.-L. Li, H. Deng, H.-W. Wang et al., "Effects of external application of chinese medicine on diabetic ulcers and the expressions of $\beta$-catenin, c-myc and K6," Chinese Journal of Integrative Medicine, vol. 17, no. 4, pp. 261-266, 2011.

[12] S. H. Yuspa, P. Hawley-Nelson, J. R. Stanley, and H. Hennings, "Epidermal cell culture," Transplantation Proceedings, vol. 12, no. 3, supplement 1, pp. 114-122, 1980.

[13] J. Sambrook, E. F. Fritsch, and T. Maniatis, Molecular Cloning: A Laboratory Manual, Cold Spring Harbor Laboratory Press, Cold Spring Harbor, NY, USA, 1989.

[14] F.-L. Li, R. Xu, Q.-C. Zeng et al., "Tanshinone IIA inhibits growth of keratinocytes through cell cycle arrest and apoptosis: underlying treatment mechanism of psoriasis," EvidenceBased Complementary and Alternative Medicine, vol. 2012, Article ID 927658, 14 pages, 2012.

[15] A. Krishan, "Rapid flow cytofluorometric analysis of mammalian cell cycle by propidium iodide staining," The Journal of Cell Biology, vol. 66, pp. 188-193, 1975.

[16] P. Friedl, K. Wolf, and J. Lammerding, "Nuclear mechanics during cell migration," Current Opinion in Cell Biology, vol. 23, no. 1, pp. 55-64, 2011.

[17] M. Simka and E. Majewski, "The social and economic burden of venous leg ulcers: focus on the role of micronized purified flavonoid fraction adjuvant therapy," American Journal of Clinical Dermatology, vol. 4, no. 8, pp. 573-581, 2003.

[18] A. S. Rao, N. Kremenevskaja, J. Resch, and G. Brabant, "Lithium stimulates proliferation in cultured thyrocytes by activating Wnt/ $\beta$-catenin signalling," European Journal of Endocrinology, vol. 153, no. 6, pp. 929-938, 2005.

[19] W. V. Welshons, K. S. Engler, J. A. Taylor, L. H. Grady, and E. M. Curran, "Lithium-stimulated proliferation and alteration of phosphoinositide metabolites in MCF-7 human breast cancer cells," Journal of Cellular Physiology, vol. 165, no. 1, pp. 134-144, 1995.

[20] A. Sun, I. Shanmugam, J. Song, P. F. Terranova, J. B. Thrasher, and $\mathrm{B}$. Li, "Lithium suppresses cell proliferation by interrupting E2F-DNA interaction and subsequently reducing S-phase gene expression in prostate cancer," Prostate, vol. 67, no. 9, pp. 976-988, 2007.

[21] J. S. Wang, C. L. Wang, J. F. Wen, Y. J. Wang, Y. B. Hu, and H. Z. Ren, "Lithium inhibits proliferation of human esophageal cancer cell line Eca-109 by inducing a G2/M cell cycle arrest," World Journal of Gastroenterology, vol. 14, no. 25, pp. 39823989, 2008.

[22] C. D. Mao, P. Hoang, and P. E. DiCorleto, "Lithium inhibits cell cycle progression and induces stabilization of p53 in bovine aortic endothelial cells," The Journal of Biological Chemistry, vol. 276, no. 28, pp. 26180-26188, 2001.

[23] C. Fathke, L. Wilson, K. Shah et al., "Wnt signaling induces epithelial differentiation during cutaneous wound healing," BMC Cell Biology, vol. 7, article 4, 2006.

[24] D. L. Zhang, L. J. Gu, L. Liu et al., "Effect of Wnt signaling pathway on wound healing," Biochemical and Biophysical Research Communications, vol. 378, no. 2, pp. 149-151, 2009.
[25] M. T. Teh, D. Blaydon, L. R. Ghali et al., "Role for WNT16B in human epidermal keratinocyte proliferation and differentiation," Journal of Cell Science, vol. 120, no. 2, pp. 330-339, 2007.

[26] S. S. Cheon, A. Y. L. Cheah, S. Turley et al., " $\beta$-Catenin stabilization dysregulates mesenchymal cell proliferation, motility, and invasiveness and causes aggressive fibromatosis and hyperplastic cutaneous wounds," Proceedings of the National Academy of Sciences of the United States of America, vol. 99, no. 10, pp. 6973-6978, 2002.

[27] I. Pastar, O. Stojadinovic, and M. Tomic-Canic, "Role of keratinocytes in healing of chronic wounds," Surgical Technology International, vol. 17, pp. 105-112, 2008. 


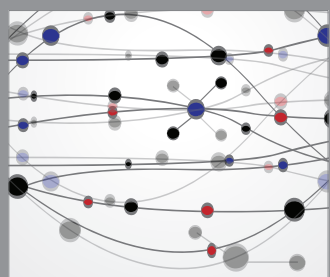

The Scientific World Journal
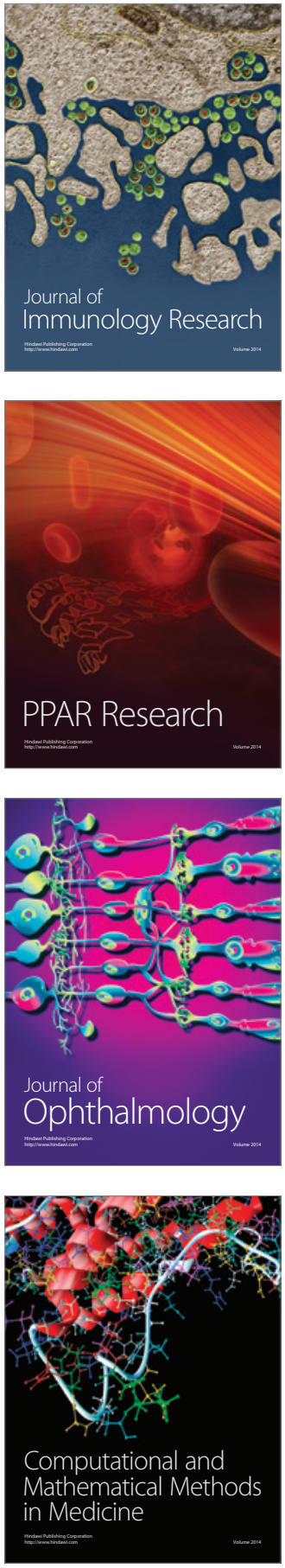

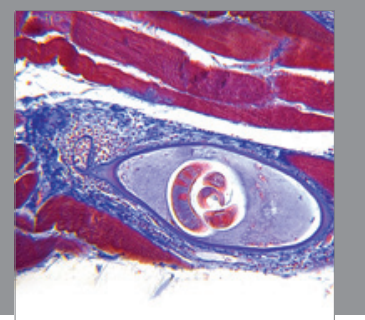

Gastroenterology

Research and Practice
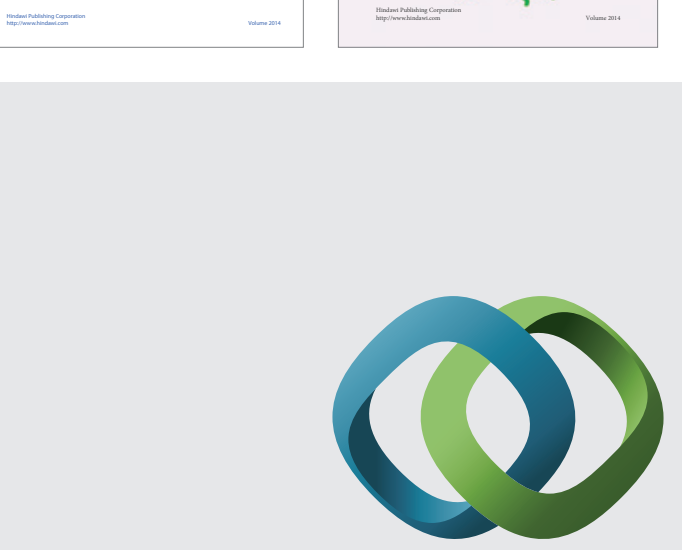

\section{Hindawi}

Submit your manuscripts at

http://www.hindawi.com
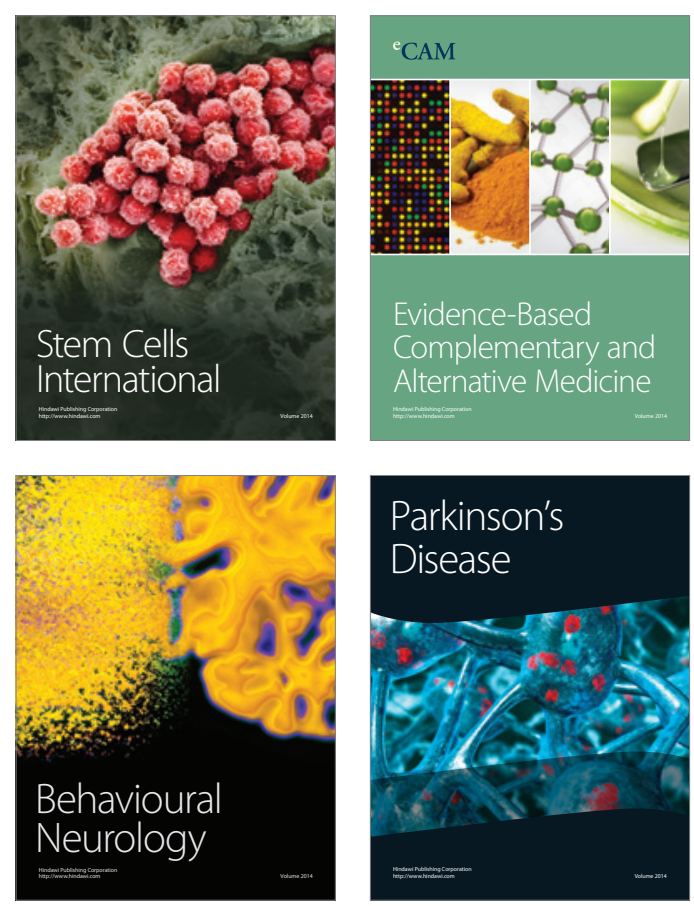

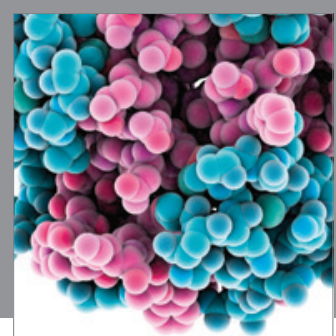

Journal of
Diabetes Research

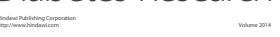

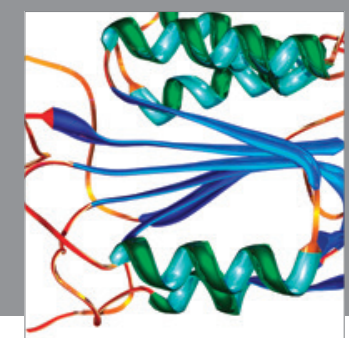

Disease Markers
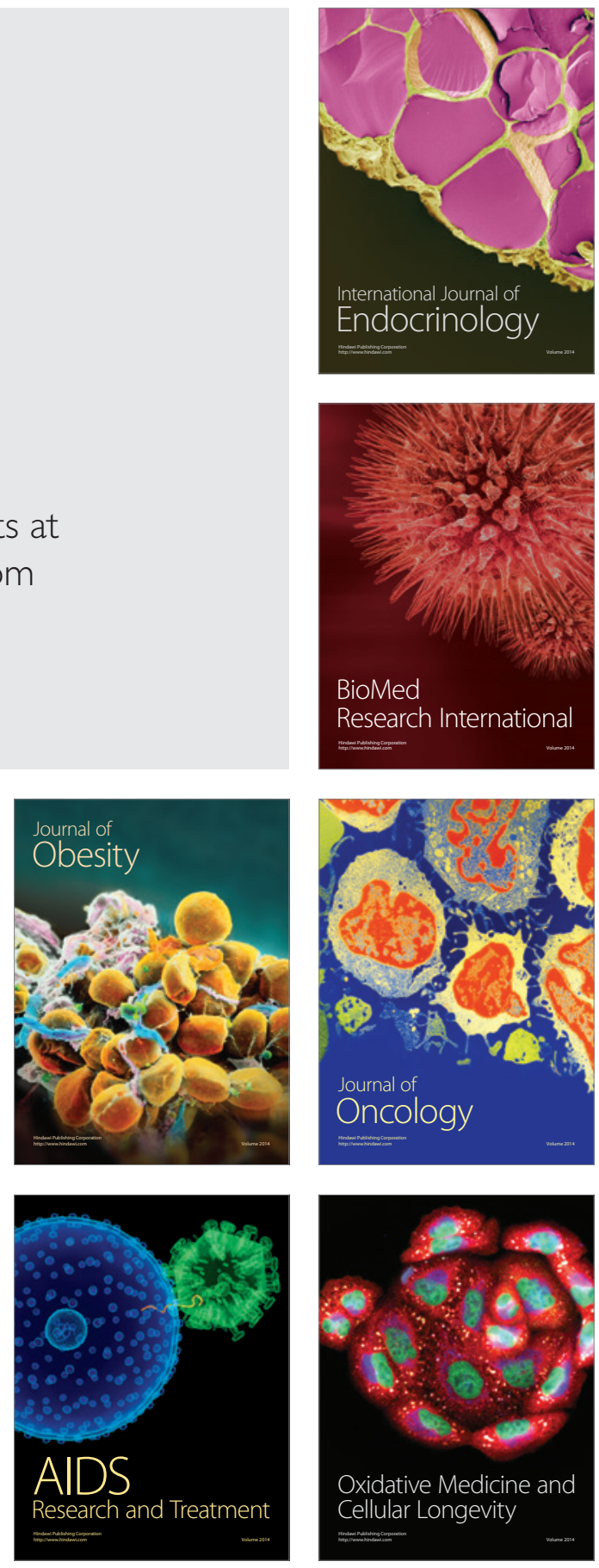